\title{
IMPLEMENTASI SUPERVISI AKADEMIK KEPALA SEKOLAH DALAM MENINGKATKAN KINERJA PENDIDIK
}

\author{
Ujang Yosep Ayubi ${ }^{1}$, Much. Tsulutsallaily Syahmuntaqy ${ }^{2}$, Ari Prayoga ${ }^{3}$ \\ 1,2Prodi MPI Program Pascasarjana UIN Sunan Gunung Djati Bandung, Indonesia \\ ${ }^{3}$ Perkumpulan Sarjana Manajemen Pendidikan Islam (PERSMAPI) Indonesia \\ yosep21al.ayyubi@gmail.com, tsulutsallaily27@gmail.com
}

\begin{abstract}
The effectiveness and intensity of principals in carrying out supervision to educators has limitations in terms of the division of tasks and time. This study aims to uncover the implementation of school principals' academic supervision in order to improve the performance of Educators in Assalaam Vocational High Schools (SMK) in Bandung, Indonesia. The research method used in this study is a qualitative method with a descriptive approach. Data collection techniques in this study used structured interviews with key informants for school principals, educators; participatory observation of supervision activities, and documentation of documents related to academic supervision. The results showed that the academic supervision process was carried out using two methods, firstly, the usual method (outside the classroom) was conducted conditionally and secondly, the clinical method (in class), carried out on a scheduled basis by the school principal or vice-principal through three stages namely, planning stage, implementation phase and evaluation stage. Educators provide a positive response to the implementation of academic supervision.
\end{abstract}

Keywords: Principal; Teacher Performance; Academic Supervision

\begin{abstract}
Abstrak : Efektivitas dan intensitas kepala sekolah dalam melaksanakan supervisi kepada para pendidik memiliki keterbatasan dalam hal pembagian tugas dan waktu. Penelitian ini bertujuan untuk mengungkap implementasi supervisi akademik kepala sekolah dalam rangka meningkatkan kinerja Pendidik di Sekolah Menengah Kejuruan (SMK) Assalaam Kabupaten Bandung, Indonesia. Metode penelitian yang digunakan pada penelitian ini adalah metode deskriptif dengan pendekatan kualitatif. Teknik pengumpulan data pada penelitian ini menggunakan wawancara terstruktur dengan key informant kepala sekolah, tenaga pendidik; observasi partisipatif kegiatan supervise, dan dokumentasi berkas-berkas yang berkaitan dengan supervise akademik. Hasil penelitian menunjukkan bahwa proses supervisi akademik dilaksanakan dengan menggunakan dua metode, pertama, metode biasa (di luar kelas) dilakukan secara kondisional dan kedua, metode klinis (dalam kelas), dilaksanakan secara terjadwal oleh kepala sekolah atau wakil kepala sekolah melalui tiga tahapan yaitu, tahap perencanaan, tahap pelaksanaan dan tahap evaluasi. Para Pendidik memberikan respon yang positif terhadap pelaksanaan supervisi akademik tersebut.
\end{abstract}

Kata Kunci: Kepala Sekolah; Kinerja Pendidik; Supervisi Akademik

Manazhim : Jurnal Manajemen dan Ilmu Pendidikan

Volume 2, Nomor 2, Agustus 2020; 118-130

https://ejournal.stitpn.ac.id/index.php/manazhim 


\section{PENDAHULUAN}

Pendidikan memiliki peran yang sangat penting bagi kehidupan setiap individu bahkan suatu bangsa. Titik berat pembangunan pendidikan pada era sekarang ditekankan pada peningkatan mutu. Pendidikan yang bermutu dapat menciptakan sumber daya manusia yang unggul dan mampu bersaing di ranah nasional maupun internasional. Demi menciptakan lulusan yang bermutu harus ditopang oleh pengelolaan sistem pendidikan melalui peningkatan sumber daya yang terlibat dalam proses pendidikan. Dalam hal ini lebih menitikberatkan pada kinerja Pendidik. Data Bappenas menyebutkan bahwa hasil survey yang dilakukan oleh UNESCO untuk kualitas kinerja Pendidik di Indonesia berada pada level 14 dari 14 negara berkembang. Hal ini menunjukkan bahwa kinerja Pendidik di Indonesia masih belum sesuai dengan yang di cita-citakan. Dengan kata lain, sebagaian Pendidik di Indonesia belum optimal dalam melaksanakan kinerja mengajarnya sesuai dengan yang diharapkan ${ }^{1}$.

Pendidik merupakan salah satu figur penting dalam meningkatkan mutu pendidikan karena Pendidik secara langsung berhadapan dengan peserta didik dalam proses belajar mengajar. Peran Pendidik menurut Imron sebagai (1) figur pembaruan; (2) berperan juga sebagai mediator yang memungkinkan terwujudnya kondisi menjadi baik dari aspek subjek peserta didik untuk transfer knowledge; (3) bertanggung jawab agar terwujudnya hasil dari pembelajaran subjek yaitu peserta didik; (4) dituntut menjadi contoh subjek didik; (5) bertanggung jawab secara professional meningkatkan kemampuannya; serta (6) menjaga kode etik secara profesinal ${ }^{2}$.

Oleh karena itu, mutu Pendidik merupakan bagian penting dari proses pembelajaran. Kemampuan tenaga pendidik dalam melaksanakan pembelajaran diharapkan mampu meningkatkan kualitas kelulusan baik dari segi kognitif, afektif dan psikomotorik serta mampu bersaing di dunia kerja. Pendidik memiliki potensi yang tinggi untuk berkreasi, berinovasi dan meningkatkan kinerja. Namun terdapat beberapa faktor yang menghambat mereka dalam mengembangkan berbagai potensi

${ }^{1}$ Edi Rismawan and others, 'Pengaruh Supervisi Kepala Sekolah Dan Motivasi Berprestasi Guru Terhadap Kinerja Mengajar Guru', Jurnal Administrasi Pendidikan, XXII.1 (2015), 114-32.

2 Teti Berliani and Rina Wahyuni, 'Impelementasi Supervisi Akademik Kepala Sekolah Dalam Meningkatkan Profesionalisme Guru', Jurnal Manajemen Dan Supervisi Pendidikan, 1.3 (2017), 218-26. 
secara optimal. Oleh karena itu, diperlukan adanya bantuan dan pembinaan secara kontinyu dan berkesinambungan dengan program yang sistematis terhadap para Pendidik di sekolah. Salah satu program pembinaan yang dapat diberikan kepada para Pendidik di sekolah yaitu melalui supervisi oleh kepala sekolah. Supervisi adalah sebagai layanan untuk membantu, mendorong, membimbing, dan membina para pendidik agar mampu meningkatkan kemampuan dan keterampilan dalam menjalankan tugas pembelajaran. Supervisi yang berkaitan dengan peningkatan potensi dan keterampilan Pendidik dalam pembelajaran yaitu supervisi akademik yang lakukan oleh kepala sekolah sebagai supervisor ${ }^{3}$.

Bambang menjelaskan bahwa supervisi akademik adalah pembinaan yang menitikberatkan pengamatan pada masa akademik yang langsung berada dalam lingkup kegiatan pembelajaran yang dilakukan oleh Pendidik-Pendidik untuk membantu siswa ketika sedang dalam proses belajar. Sejalan dengan itu Permen diknas nomor 13 tahun 2007 menyatakan bahwa kepala sekolah harus kompeten dalam melakukan supervisi akademik, meliputi ${ }^{4}$ (1) merencanakan program dari supervisi akademik dalam upaya meningkatkan profesionalisme dari pendidik; (2) melaksanakan program supervisi akademik terhadap pendidik dengan melalui pendekatan serta teknik supervisi yang tepat sasaran; (3) menindaklanjuti hasil dari program supervisi akademik terhadap Pendidik dalam rangka peningkatan kemampuan profesionalisme pendidik.

Tujuan supervisi yaitu membantu tenaga pendidik mengembangkan kemampuannya untuk mencapai tujuan dari pembelajaran yang harus dicapai oleh peserta didik. Dengan peningkatan kompetensi pengetahuan serta keterampilan Pendidik mengajar, meningkatkan komitmen (commitment) kerja, dan kemauan (willingness) kerja serta motivasi (motivation) kerja Pendidik, sebab dengan peningkatan dari kemampuan dan motivasi kerja Pendidik, maka aka nada peningkatan kualitas pembelajaran. Tujuan supervisi yang lebih utama yaitu untuk membantu tenaga

3 Leniwati dan Yasir Arafat, 'Implementasi Supervisi Akademik Kepala Sekolah Untuk Meningkatkan Kinerja Guru', Jurnal Manajemen Dan Supervisi Pendidikan, 2.1 (2017), 106-14

4 Wiyono, Bambang, 'Hakikat Kepemimpinan Transformasional', INTIZAM: Jurnal Manajemen Pendidikan Islam, 2.2 (2018), 74-83 
Pendidik dalam mengembangkan kemampuan dan kreativitas ketika mencapai tujuan dari pembelajaran ${ }^{5}$.

Berdasarkan latar belakang penelitian diatas maka perlu adanya kajian lebih medalam terkait supervisi yang dilakukan oleh kepala sekolah pada jenjang Sekolah Menengah Kejuruan dalam meningkatkan kinerja para pendidik.

\section{METODE PENELITIAN}

Penelitian ini bertujuan untuk mengungkap bagaimana implementasi supervisi akademik yang dilakukan kepala sekolah sebagai upaya peningkatan kinerja Pendidik dalam rangka meningkatkan mutu pendidikan SMK Assalaam Kabupaten Bandung. Penelitian ini menggunakan metode penelitian deskriptif dengan pendekatan kualitatif, yaitu prosedur penelitian yang dapat menghasilkan data deskriptif berupa kata-kata tertulis atau tulisan dari responden atau dari orang-orang yang perilakunya diamati ${ }^{6}$. Penelitian ini dilakukan di SMK Assalaam Kecamatan Cibaduyut Kabupaten Bandung, Indonesia. Penelitian ini mendeskripsikan berbagai hal yang berkaitan dengan fokus permasalahan yang diteliti. Adapun teknik pengumpulan data pada penelitian ini yaitu ${ }^{7}$; (1) observasi kegiatan supervisi yang dilaksanakan kepala sekolah pada saat pembelajaran, (2) wawancara dengan responden yang berperan aktif pada pembahasan penelitian dengan key informant yaitu kepala sekolah dan snowball process bersama wakil kepala sekolah bidang kurikulum dan para Pendidik sebagai sumber utama dalam penelitian., (3) Studi dokumentasi, mengumpulkan dan mengamati dokumentasi yang tersedia dari proses supervisi yang telah dilakukan. Uji absah data menggunakan kredibiliti Bersama internal para informan, konfirmabiliti data yang masuk dari responden dengan eksternal, transfermabiliti data yang telah

${ }^{5}$ Desi Ratnasari dkk, 'Implementasi Teknik Supervisi Akademik Kepala Sekolah Terhadap Pendidik Di Sekolah Dasar Untuk Menghadapi Era Digital', Jurnal Manajemen Dan Supervisi Pendidikan Volume 3 Nomor 1 November 2018 Tersedia, 3.November (2018), 1-4

${ }^{6} \mathrm{~J}$. H McMillan and S Schumacher, 'Research in Education. A Conceptual Introduction', Research Design and Methodology, $2001<$ https://doi.org/10.4324/9781315203362-5>; Terry Anderson and Julie Shattuck, 'Design-Based Research: A Decade of Progress in Education Research?', Educational Researcher, 2012 <https://doi.org/10.3102/0013189X11428813>. 2017.

${ }^{7}$ Lexy J. Moleong, 'Metodologi Penelitian Kualitatif (Edisi Revisi)', in PT. Remaja Rosda Karya, 
diolah bersama para narasumber penelitian dan reabiliti untuk hasil penelitian bersama tim peneliti ${ }^{8}$.

\section{HASIL PENELITIAN DAN PEMBAHASAN}

Permasalahan sumber daya manusia (SDM) masih menjadi sororan dan tumpuan bagi sekolah. Sumber daya manusia merupakan investasi jangka panjang sekolah yang memerlukan upaya besar dalam mengembangkan potensinya. Diperlukan berbagai upaya waktu, kesabaran dan metode yang tepat untuk meningkatkan kinerja SDM sekolah ke arah yang diinginkan. Kinerja Pendidik merupakan hasil kerja secara kualitas dan kuantitas yang dicapai oleh seorang Pendidik dalam melaksanakan tugasnya sesuai dengan tanggung jawab yang diberikan kepadanya ${ }^{9}$.

Pelaksanaan supervisi haruslah dilakukan secara sistematis dengan perencanaan yang baik oleh kepala sekolah atau pengawas sekolah agar tujuan awal dari supervisi yaitu untuk memberikan pembinaan kepada Pendidik bias berjalan secara efektif dan efisien. Di dalam lapangan, kepala sekolah dan pengawas sekolah menggunakan lembar pengamatan berupa modul yang berisi aspek-aspek yang harus diperhatikan dalam proses pengamatan. Dalam mengamati Pendidik, digunakan lembar observasi berupa alat penilaian kinerja Pendidik atau lembar penilaian kemampuan Pendidik, sedangkan dalam mengamati sekolah, seorang pengawas menggunakan lembar observasi/pengamatan untuk bidang akademik, kesiswaaan, personalia, keuangan, sarana dan prasarana serta hubungan masyarakat ${ }^{10}$.

Berdasarkan hasil wawancara dengan kepala SMK Assalaam Kabupaten Bandung dihasilkan data bahwa dalam pelaksanaan supervisi akademik dilakukan oleh kepala sekolah dan wakil kepala sekolah bidang kurikulum apabila kepala

\footnotetext{
${ }^{8}$ Sugiyono, Metode Penelitian Kuantitatif, Kualitatif Dan R\&D, 24th edn (Bandung: Alfabeta, 2016).

9 Ari Prayoga and Supiana, 'Supervisi Akademik Kepala Madrasah', INOVATIF: Jurnal Penelitian Pendidikan, Agama Dan Kebudayaan, $06.01 \quad$ (2020), 105-24 <http://www.jurnal.staih.ac.id/index.php/inovatif/article/view/106>.

10 Alfiyan Paramudita and Iwan Ridwan, 'Teknik Supervisi Akademik Di Sekolah Islam', Madrasa: Journal of Islamic Educational Management, $2.1 \quad$ (2019), 1-6 <https://doi.org/10.32940/mjiem.v2i1.91>.
} 
sekolah berhalangan hadir pada saat supervisi akademik yang telah ditentukan jadwalnya. Dalam pelaksanaan supervisi akademik dilakukan dengan cara yang sistematis yaitu dengan cara menyusun perencanaan terlebih dahulu, selanjutnya pelaksanaan kemudian menindaklanjuti serta evaluasi dari pelaksanaan supervisi akademik tersebut. Dengan demikian dapat kita simpulkan bahwa pelaksanaan supervisi akademik di SMK Assalaam Kabupaten Bandung dilakukan melalui 3 (tiga) tahap yaitu perencanaan, pelaksanaan dan evaluasi. Hal ini sesuai dengan pendapat asmendri bahwa pelaksanaan supervisi akademik terdiri dari tiga tahapan yaitu perencanaan, pelaksanaan dan evaluasi.

\section{Perencanaan Supervisi Akademik}

Pada tahap perencanaan supervisi ada beberapa hal yang harus dilakukan, yaitu penentuan tujuan, waktu pelaksanaan, sumber daya manusia sebagai pelaksana dan pembuatan jadwal supervisi. Berdasarkan wawancara dengan wakil kepala sekolah bidang kurikulum Iik Hikmat beliau menyampaikan bahwa kegiatan pada tahap perencanaan adalah menentukan tujuan supervisi dan menyusun jadwal yang telah tercantum pada Surat Keputusan (SK) tentang supervisi akademik disertai dengan pemberitahuan jadwal pelaksanaannya untuk setiap Pendidik mata pelajaran bersangkutan. Hal tersebut diperkuat dengan wawancara Bersama beberapa Pendidik di SMK Assalaam Kabupaten Bandung, diantaranya; Maya Puspita Ihya Ulumuddin dan Tammy Ayundari Mereka mengatakan bahwa dalam proses pelaksanaan supervisi akademik tersebut, sebelumnya mereka telah mendapatkan informasi melalui kepala sekolah dan wakil kepala sekolah bidang kurikulum kemudian diberikan surat keputusan (SK) tentang kegiatan supervisi akademik yang dilampiri dengan jadwal pelaksanaan supervisi masing-masing. Hal tersebut dilakukan supaya Pendidik-Pendidik dapat mempersiapkan diri dan mengetahui jadwal pelaksanaan supervisi masing-masing sesuai jadwal yang telah ditentukan. Kegiatan tersebut sesuai dengan pendapat Asmendri bahwa hal yang harus dicantumkan dalam proses perencanaan supervisi yaitu meliputi tujuan supervisi, kegiatan tersebut dilaksanakan, metode atau teknik untuk mencapai tujuan yang sebelumnya dirumuskan, siapa saja yang akan ikut dilibatkan, waktu dan estimasi pelaksanaan, dan aspek-aspek yang 
diperlukan dalam proses pelaksanaannya serta bagaimana cara memperoleh hal-hal tersebut.

Aktivitas supervisi yang terlaksana meliputi: merangsang dan membangkitkan ghiroh atau semangat Pendidik dan tenaga kependidikan dalam menjalankan tugasnya dengan optimal; mencari dan mengembangkan metode-metode pembelajaran kontemporer yang lebih baik dan sesuai dalam proses kegiatan belajar mengajar (KBM); mengembangkan hubungan kerjasama antara Pendidik dan siswa, Pendidik dan sesama Pendidik, Pendidik dan kepala sekolah serta seluruh staf sekolah yang terlingkup atau berada di lingkungan sekolah; senantiasa berusaha meningkatkan kualitas pengetahuan dan wawasan Pendidik serta tenaga kependidikan melalui pembinaan berkala, baik dalam bentuk seminar, forum group disscution (FGD), worshop, in service trining, upgrading, dan lain sebagainya ${ }^{11}$.

\section{Pelaksanaan Supervisi Akademik}

Pelaksanaan supervisi di SMK Assalaam Kabupaten Bandung, terdapat dua macam metode supervisi yang digunakan, yaitu supervisi biasa (di luar kelas) dan supervisi klinis (dalam kelas). Namun pada pelaksanaannya lebih difokuskan pada supervisi di dalam kelas ketika kegiatan pembelajaran yang diagendakan minimal satu kali pada setiap semesternya. Supervisi biasa dilakukan dalam bentuk kegiatan yang dapat membantu Pendidik dalam mengatasi permasalahan-permasalahan dan kesulitan-kesulitan yang dihadapi Pendidik seperti melakukan diskusi mengenai metode pembelajaran yang tepat dan wawancara dengan Pendidik mengenai hal lain yang berkenaan dengan proses pembelajaran dan kinerja Pendidik disekolah. Hal ini secara kondisional tidak ada jadwal tertentu namun dilakukan secara mendadak atau ketika dibutuhkan oleh kepala sekolah atau maupun Pendidik itu sendiri dalam memecahkan suatu persoalan dan kesulitan yang dialami. Sementara itu supervisi klinis (dalam kelas) dilakukan sesuai dengan yang telah ditentukan oleh pihak sekolah melalui surat keputusan (SK) kepala sekolah sehingga para Pendidik tidak terkejut saat kepala sekolah datang ke kelas masing-masing ketika Pendidik menyampaikan materi kepada peserta didik untuk disupervisi akademik oleh kepala sekolah.

11 Sahmudin Sahmudin and Ari Prayoga, 'Meningkatkan Kompetensi Pedagogik Pendidik Dalam Pembelajaran Melalui Supervisi Akademik', Al-Mau'iz̧hoh, $1.2 \quad$ (2019) <https://www.jurnal.unma.ac.id/index.php/am/article/view/1673>. 
Berdasarkan hasil wawancara dengan kepala SMK Assalaam kabupaten Bandung, pada supervisi klinis ini peneliti mengetahui bahwa pelaksanaan kegiatan ini dilakukan dengan cara langsung menyaksikan di dalam kelas saat para Pendidik mengajar. Sebelum dimulai, kepala sekolah melakukan pra observasi seperti memeriksa kesiapan Pendidik, menelaah dan mempelajari RPP yang akan diajarkan kepada peserta didik. Ketika kegiatan supervisi klinis berlangsung kepala sekolah memerhatikan cara para Pendidik mengajar, seperti tujuan pembelajaran, metode yang digunakan, dinamika dalam pembelajaran dan kesesuaian antara RPP yang telah disusun dengan penyampaian ketika mengajar di kelas ${ }^{12}$.

Setelah melakukan pengamatan dan cara mengajar Pendidik di kelas, selanjutnya kepala sekolah memanggil Pendidik ke ruang tertentu yang telah disiapkan untuk menyampaikan hasil dari supervisi tersebut. Kepala sekolah berdiskusi dengan Pendidik yang telah disupervisi mengenai kondisi selama pembelajaran berlangsung dan memberikan solusi dari permasalahan yang terjadi. Hal tersebut diperkuat berdasarkan wawancara dengan seorang Pendidik, yaitu Ihya Ulumuddin yang menyatakan bahwa setelah melakukan pengamatan di dalam kelas kemudian setiap Pendidik dipanggil oleh kepala sekolah keruangan yang telah di siapkan untuk mendiskusikan hasil dari pengamatan ketika supervisi tersebut berlangsung. Setelah itu kepala sekolah menyampaikan kelebihan yang dimiliki Pendidik dalam mengajar, memberikan masukan dan dan solusi terhadap kelemahan dan kekurangan Pendidik dalam mengajar kepada peserta didiknya. Hal tersebut terdapat kesamaan dengan pendapat, yang mengungkapkan bahwa pelaksanaan supervisi meliputi beberapa kegiatan seperti pengumpulan data, penilaian, deteksi kelemahan, memperbaiki kelemahan, bimbingan dan pengembangan ${ }^{13}$.

Hal yang diukur di dalam supervisi pendidikan meliputi kepemimpinan dan pengawasan. Fungsi kepemimpinan harus melekat di dalam seorang supervisor karena ia merupakan seorang pemimpin secara struktural, pun demikian fungsi pengawasan, karena secara hakikat supervisor merupakan pengawas yang tugas

12 Dian Dian and Ari Prayoga, 'Supervisi Akademik Kepala Madrasah Di Madrasah Aliyah Darussalam Sumedang', Briliant: Jurnal Riset Dan Konseptual, 04.04 (2019), 548-58 <https://doi.org/10.28926/briliant.v4i4.413>.

13 Asmendri, Teori Dan Aplikasi Manajemen Peningkatan Mutu Pendidikan Sekolah/Madrasab (Batu Sangkar: STAIN Batu Sangkar Press, 2012) 
pokoknya adalah mengawasi atau pengawasan. Pengawasan merupakan fungsi tugas pelaksana dari supervisor. Kepala sekolah merupakan seseorang yang mempunyai tugas sebagai pemimpin di lembaga pendidikan formal. Pemimpin yang dapat menumbuhkan, memelihara dan mengembangkan usaha serta iklim organisasi di lembaga pendidikan dapat dikatakan sebagai pemimpin yang efektif. Untuk mencapai tujuan yang lebih baik, hendaklah seorang pemimpin mampu memimpin dan memengaruhi bawahannya untuk bekerjasama dalam mencapai tujuan yang telah disepakati sebelumnya. Kepemimpinan adalah sifat atau kemampuan yang dimiliki oleh seorang pemimpin yang bergina untuk memengaruhi orang-orang yang dipimpinnya. Ciri kepemimpinan supervisor pendidikan adalah memiliki kemampuan untuk meningkatkan semangat kerja, mendorong kreativitas, mengakomodir, membimbing serta memberikan suri teladan kepada bawahannya ${ }^{14}$.

Begitu pentingnya supervisor/pengawas dalam mendorong perkembangan kualitas pendidikan dan pembelajaran di sekolah, maka saat ini pengewas telah ditetapkan sebagai pejabat fungsioal penuh yang konsekuensinya adalah bahwa setiap pengawasan haruslah berdasarkan pada wawasan dan kemampuan profesional yang melebihi wawasan dan kemampuan profesional seorang kepala sekolah, Pendidik, dan tenaga kependidikan dalam bidang pendidikan. Begitupun kepala sekolah, saat ini fungsinya sebagai pengawas internal sekolah dengan ditanggalkannya kewajiban mengajar dan agar hanya terfokus pada manajerial sekolah yang di dalamnya tentu merupakan fungsi pengawasan, maka kepala sekolah wajib memiliki kompetensi, wawasan dan kemampuan di atas para Pendidik di bawahnya ${ }^{15}$.

\section{Evaluasi Supervisi Akademik}

Selanjutnya tahapan evaluasi, tahap ini dalam supervisi merupakan tahap penilaian setiap kegiatan yang telah dilaksanakan, apakah supervisi tersebut sudah sesuai dengan tujuan yang ditetapkan atau belum. Sejalan dengan itu, Teti Berliana \&

${ }^{14}$ Nasir Usman, Niswanto Ajasan, 'Efektivitas Pelaksanaan Supervisi Akademik Oleh Kepala Sekolah Dalam Meningkatkan Kinerja Guru Di Smk Negeri 1 Meulaboh.', Jurnal Administrasi Pendidikan : Program Pascasarjana Unsyiah, 2016.

15 Badrudin Badrudin and others, 'Pengaruh Kepemimpinan Kepala Sekolah Dan Kelompok Kerja Guru Terhadap Kinerja Guru Sekolah Dasar', Tadbir: Jurnal Manajemen Pendidikan Islam, 08.01 (2020), 66-75 <http://journal.iaingorontalo.ac.id/index.php/tjmpi/article/view/1151>. 
Rina Wahyuni ${ }^{16}$ menyatakan bahwa evaluasi terhadap kegiatan supervisi ini dilakukan untuk mengetahui tingkat keberhasilan dari kegiatan supervisi itu sendiri; maksudnya di sini adalah tingkat keberhasilan yang dilihat dari berbagai aspek yang menunjang dalam proses belajar mengajar, baik itu dari segi personal (Pendidik dan peserta didik), sarana prasarana penunjang kegiatan belajar mengajar (KBM) dan segi pelaksanaan KBM (operasional). Evaluasi pada supervisi lebih dikenal dengan tindak lanjut yang digunakan untuk meningkatkan kompetensi dan kinerja Pendidik apabila permasalahan yang dihadapi Pendidik belun terselesaikan. Seperti pernyataan Leniwati tindak lanjut yang dilaksanakan apabila dalam pelaksanaan supervisi telah diberikan masukan tetapi permasalahan belum dapat diatasi maka Pendidik yang bersangkutan akan diikutsertakan dalam kegiatan ilmiah, seperti MGMP, workshop, pelatihan, seminar dan lain-lain untuk meningkatkan pengetahuan dan keterampilan Pendidik. Hal tersebut sejalan dengan apa yang disampaikan para pendidik SMK Assalaam Kabupaten Bandung yaitu, Maya Muspita, Sopwan Munawar, dan Isma Nuryanti bahwa evaluasi atau tindak lanjut dari supervisi yang laksanakan, selain masukan dari kepala sekolah juga setiap Pendidik diberikan kesempatan mengikuti kegiatan In House Traning (IHT), MGMP, seminar, training dan lain-lain untuk meningkatkan dan mengembangkan kompetensi dan keterampilan Pendidik dalam proses pembelajaran terhadap peserta didik.

Berdasarkan hasil wawancara dengan kepala sekolah tentang respon Pendidik terhadap kegiatan supervisi akademik tersebut, beliau meyampaikan bahwa para Pendidik memberikan respon positif. Hal ini senada dengan penellitian yang dilakukan oleh Jumadiah, $\mathrm{dkk}^{17}$ yang menemukan bahwa Pendidik sangat merespon positif kegiatan supervisi akademik yang dilakukan oleh kepala sekolah. Hal tersebut diperkuat oleh beberapa pernyataan Pendidik yaitu: Yanti Novianty, Tammy Ayundari dan Ihya Ulumuddin bahwa kegiatan supervisi yang dilakukan kepala sekolah terhadap Pendidik sangat penting, selain kegiatan tersebut merupakan tugas kepala sekolah juga dapat memberikan semangat para pendidik untuk Menyusun

16 Guntur Abdul Yunus, Wahyu Lestari, and Tri Joko Raharjo, 'Pengembangan Model Supervisi Akademik Berbasis Evaluasi Diri Bagi Guru SMA', Educational Management, 2016.

17 Nur'ani, jumadiah dkk, 'Impelementasi Supervisi Akademik Kepala MIS Batusangkar', Jurnal Manajemen Dan Supervisi Pendidikan, 1.2 (2016), 12-25 
rencana perangkat pembelajaran (RPP) yang baik, menggunakan metode yang tepat saat mengajar dan meningkatkan keterampilan Pendidik dalam proses pembelajaran.

Tujuan dari penilaian kinerja Pendidik adalah untuk mengevaluasi secara sistematis sifat dan perilaku individu karyawan atau Pendidik yang mempengarugi kinerjanya. Evaluasi adalah upaya menyediakan informasi untuk disampaikan kepada pengambil keputusan. Secara terperinci, Suprihanto menyatakan bahwa tujuan penilaian pelaksanaan pekerjaan atau kinerja adalah sebagai berikut ${ }^{18}$ : Mengetahui keterampilan dan kemampuan pegawai secara komprehensif; Menjadi bahan dasar perencanaan bidang personalia, khususnya dalam upaya penyempurnaan kondisi kerja, peningkatan mutu kerja dan hasil kerja; Menjadi bahan dasar pengembangan dan pendayagunaan pegawai seoptimal mungkin sehingga antara lain dapat diarahkan jenjang kariernya atu perencanaan karier, kenaikan pangkat, kenaikan jabatan; Mendorong lahirnya timbal balik yang baik dan sehat antara Pendidik dan atasan; Bagi pegawai, hal ini dapat dijadikan sebagai bahan evaluasi diri untuk mengetahui potensi, kelebihan dan kekurangan; Bagi pengawas, hal ini dapat dijadikan sebagai bahan untuk lebih mengenal dan memperhatikan bawahannya.

Dapat disimpulkan bahwa kegiatan supervisi akademik yang dilakukan kepala sekolah terhadap Pendidik-Pendidik di SMK Assalaam Kabupaten Bandung melalui tahapan dan prosedur yang telah ditetapkan oleh sekolah dapat meningkatkan kompetensi dan keterampilan Pendidik dalam melaksanakan kegiatan pembelajaran terhadap peserta didik serta dapat meningkatkan kualitas kinerja Pendidik menjadi lebih baik. Hal tersebut sesuai dengan hasil penelitian Joni (2016) yang menyimpulkan bahwa supervisi sangat penting dilakukan oleh kepala sekolah dalam rangka meningkatkan kualitas kinerja Pendidik.

18 Darto, 'Supervisi Akademik Terprogram Dalam Peningkatan Kompetensi Guru Pada Pelaksanaan Pembelajaran', Jurnal Penelitian Tindakan Sekolah Dan Kepengawasan, 2014. 


\section{KESIMPULAN}

Supervisi akademik sebagai layanan bimbingan dan pembinaan kepala sekolah kepada para Pendidik di SMK Assalaam Kabupaten Bandung dilaksanakan melalui tiga tahapan yaitu, pertama, perenacanaan supervisi diawali dengan sosialisasi dan informasi pelaksanaan supervisi, pemberian jadwal supervisi untuk setiap Pendidik agar para Pendidik mempersiapkan RPP, metode dan hal lain demi mendukung pelaksanaan supervisi tersebut. Kedua, pelaksanaan supervisi akademik dilaksanakan oleh kepala sekolah atau wakil kepala sekolah bidang kurikulum baik di dalam kelas atau di luar kelas namun lebih difokuskan pada pelaksanaan supervisi di dalam kelas ketika proses pembelajaran karena dianggap lebih efektif untuk melihat kekurangan dan kelebihan kinerja Pendidik dalam mengajar dan memberikan materi kepada peserta didik. Ketiga, evaluasi sebagai tindak lanjut dari hasil pelaksanaan supervisi akademik dilakukan untuk mengetahui kekurangan dan kelebihan Pendidik dalam mengajar kemudian kepala sekolah menilai dan memberikan masukan serta arahan untuk memecahkan masalah yang dihadapi dalam rangka peningkatan kompetensi kinerja Pendidik dalam mengajar sehingga dapat menghasilkan lulusan yang berkualitas.

\section{DAFTAR PUSTAKA}

Ajasan, Nasir Usman, Niswanto, 'Efektivitas Pelaksanaan Supervisi Akademik Oleh Kepala Sekolah Dalam Meningkatkan Kinerja Guru Di SMK Negeri 1 Meulaboh.', Jurnal Administrasi Pendidikan : Program Pascasarjana Unsyiah, 2016

Anderson, Terry, and Julie Shattuck, 'Design-Based Research: A Decade of Progress in Education Research?', Educational Researcher, 2012 <https://doi.org/10.3102/0013189X11428813>

Asmendri, Teori Dan Aplikasi Manajemen Peningkatan Mutu Pendidikan Sekolah/Madrasah (Batu Sangkar: STAIN Batu Sangkar Press, 2012)

Badrudin, Badrudin, Teti Muliawati, Yunus Russamsi, and Ari Prayoga, 'Pengaruh Kepemimpinan Kepala Sekolah Dan Kelompok Kerja Guru Terhadap Kinerja Guru Sekolah Dasar', Tadbir: Jurnal Manajemen Pendidikan Islam, 08.01 (2020), 66-75 <http://journal.iaingorontalo.ac.id/index.php/tjmpi/article/view/1151>

Berliani, Teti, and Rina Wahyuni, 'Impelementasi Supervisi Akademik Kepala Sekolah Dalam Meningkatkan Profesionalisme Guru', Jurnal Manajemen Dan Supervisi Pendidikan, 1.3 (2017), 218-26 
Darto, 'Supervisi Akademik Terprogram Dalam Peningkatan Kompetensi Guru Pada Pelaksanaan Pembelajaran', Jurnal Penelitian Tindakan Sekolah Dan Kepengawasan, 2014

Desi Ratnasari dkk, 'Implementasi Teknik Supervisi Akademik Kepala Sekolah Terhadap Pendidik Di Sekolah Dasar Untuk Menghadapi Era Digital', Jurnal Manajemen Dan Supervisi Pendidikan Volume 3 Nomor 1 November 2018 Tersedia, 3.November (2018), 1-4

Dian, Dian, and Ari Prayoga, 'Supervisi Akademik Kepala Madrasah Di Madrasah Aliyah Darussalam Sumedang', Briliant: Jumal Riset Dan Konseptual, 04.04 (2019), 548-58 < https://doi.org/10.28926/briliant.v4i4.413>

Leniwati dan Yasir Arafat, 'Implementasi Supervisi Akademik Kepala Sekolah Untuk Meningkatkan Kinerja Guru', Jurnal Manajemen Dan Supervisi Pendidikan, 2.1 (2017), 106-14

McMillan, J. H, and S Schumacher, 'Research in Education. A Conceptual Introduction', Research Design and Methodology, 2001 $<$ https://doi.org/10.4324/9781315203362-5>

Moleong, Lexy J., 'Metodologi Penelitian Kualitatif (Edisi Revisi)', in PT. Remaja Rosda Karya, 2017

Nur'ani, jumadiah dkk, 'Impelementasi Supervisi Akademik Kepala MIS Batusangkar', Jurnal Manajemen Dan Supervisi Pendidikan, 1.2 (2016), 12-25

Paramudita, Alfiyan, and Iwan Ridwan, 'Teknik Supervisi Akademik Di Sekolah Islam', Madrasa: Journal of Islamic Educational Management, 2.1 (2019), 1-6 <https://doi.org/10.32940/mjiem.v2i1.91>

Prayoga, Ari, and Supiana, 'Supervisi Akademik Kepala Madrasah', INOVATIF: Jurnal Penelitian Pendidikan, Agama Dan Kebudayaan, 06.01 (2020), 105-24 <http://www.jurnal.staih.ac.id/index.php/inovatif/article/view/106>

Rismawan, Edi, Berprestasi Guru, Berprestasi Guru, and Motivasi Berprestasi Guru, 'Pengaruh Supervisi Kepala Sekolah Dan Motivasi Berprestasi Guru Terhadap Kinerja Mengajar Guru', Jurnal Administrasi Pendidikan, XXII.1 (2015), 114-32

Sahmudin, Sahmudin, and Ari Prayoga, 'Meningkatkan Kompetensi Pedagogik Pendidik Dalam Pembelajaran Melalui Supervisi Akademik', Al-Mau'į̧hoh, 1.2 <https://www.jurnal.unma.ac.id/index.php/am/article/view/1673>

Sugiyono, Metode Penelitian Kuantitatif, Kualitatif Dan R\&D, 24th edn (Bandung: Alfabeta, 2016)

Wiyono, Bambang, 'Hakikat Kepemimpinan Transformasional', INTIZAM: Jurnal Manajemen Pendidikan Islam, 2.2 (2018), 74-83

Yunus, Guntur Abdul, Wahyu Lestari, and Tri Joko Raharjo, 'Pengembangan Model Supervisi Akademik Berbasis Evaluasi Diri Bagi Guru SMA', Educational Management, 2016 